\title{
Aneuploidy Screening in the First Trimester
}

\author{
KEVIN SPENCER*
}

This article reviews the performance of first trimester screening for chromosomal anomalies using various combinations of ultrasound and maternal serum biochemical modalities. Detection rates in excess of $90 \%$ can be routinely achieved for Trisomy 21, Trisomy 13, Trisomy 18 using a combination of fetal nuchal translucency (NT) thickness and maternal serum free B-hCG and PAPP-A at $11+0$ to $13+6$ weeks of gestation.

(c) 2007 Wiley-Liss, Inc.

KEY WORDS: trisomy 21; trisomy 18; trisomy 13; nuchal translucency

\section{How to cite this article: Spencer K. 2007. Aneuploidy screening in the first trimester. Am J Med Genet Part C Semin Med Genet 145C:18-32.}

\section{INTRODUCTION}

The aim of prenatal screening programs is to further refine a woman's risk for carrying a fetus with a chromosomal

Professor Spencer is the Head of Department of Clinical Biochemistry to Barking, Havering \& Redbridge Hospitals NHS Trust, serving a population of 0.75 million people in one of the largest NHS Trusts in the UK. He is also Director of the Prenatal Screening Unit which provides prenatal screening services for 25,000 pregnancies per year. The Prenatal Research Unit attached to Professor Spencer's department has published extensively in the area of 2 nd trimester and 1st trimester screening for chromosomal anomalies, and more recently, the work of his unit is focused on pregnancy complications. Professor Spencer and his unit attract grant funding from the MRC, Wellcome Trust, NHS R\&D and from the European Union, and he has published over 250 papers in this area. Professor Spencer works collaboratively with Professor Kypros NicolaidesProfessor of Fetal Medicine, Harris Birthright Research Centre for Fetal Medicine, Kings College Hospital, London, where Professor Spencer is a Visiting Professor in Reproduc tive Biochemistry. Professor Spencer is also Director of Biochemical Screening at the Fetal Medicine Foundation-a charity whose role is to set standards, train, educate and carry out research in aspects of Maternal Fetal Medicine.

*Correspondence to: Prof. Kevin Spencer, Prenatal Screening Unit, Clinical Biochemistry Department, Harold Wood Hospital Gubbins Lane, Romford RM3 OBE, UK.

E-mail: kevinspencer1@aol.com

DOI 10.1002/ajmg.c.30119 anomaly beyond that of age alone. Based on such information, an invasive diagnostic test such as amniocentesis or chorionic villus sampling (CVS) can be offered to determine the actual fetal karyotype. Presently, such invasive procedures remain the definitive test for fetal aneuploidies. However, these procedures themselves carry a potential fetal loss rate, which while small may be unacceptable to certain women. Therefore, prenatal screening programs provide information with which couples can make appropriate informed choices about reproductive decisions, rather than focusing on disabilities and their eradication [Royal College of Obstetricians and Gynaecologists, 1997].

The natural frequency of chromosomal abnormalities at birth, in the absence of any prenatal diagnosis, has been estimated at 6 per 1,000 births. The aneuploides are the most frequent of these, with trisomy 21 (Down syndrome) the most common, with an often-quoted birth prevalence of 1 in 800 [Hook, 1992]. The other common autosomal trisomies including trisomy 18 (Edward syndrome) and trisomy 13 (Patau syndrome) occur with birth incidences of 1 in 6,500 and 1 in 12,500 , respectively. The other group of aneuploides includes the sex aneuploides, such as Turner syndrome (45,
X0), Klinefelter syndrome (47,XXY), and Type I (diandry) and II (digyny) Triploidy.

The incidence of the major trisomies (13, 18, and 21) increases dramatically with advancing maternal age and since there has been a shift over the past 20 years to women having babies at an older age, the general prevalence has increased such that the birth prevalence for trisomy 21 has increased from 1 in 740 in 1974 to 1 in 504 by 1997 [Egan et al., 2000]. Although the birth incidence of the major chromosomal abnormalities approaches 6 per 1,000, the actual frequency at any one time in pregnancy varies due to the varying intrauterine lethality of the various conditions. This means that when screening women in early pregnancy, there are a significantly greater number of fetuses affected than at term or midgestation. Thus, for trisomy 21 , there is a $40 \%$ fetal loss between 12 weeks and term, and a 30\% fetal loss between 16 weeks and term. For trisomies 13 or 18 , there is an $80 \%$ fetal loss between 12 weeks and term, and a $40 \%$ fetal loss between 16 weeks and term [Snijders et al., 1995].

Screening for Down syndrome over the past two decades has become an established part of obstetric practice in many developed countries, primarily 
through the use of maternal serum biochemical screening in the second trimester of pregnancy. In the second

\section{Screening for Down syndrome over the past two decades has become an established part of obstetric practice in many developed countries, primarily through the use of maternal serum biochemical screening \\ in the second trimester of pregnancy.}

trimester, a range of maternal serum biochemical markers have been investigated, but routine screening has come to rely on the use of a combination of two, three, or four markers. The concentration of many of the biochemical markers varies with the duration of pregnancy. By expressing the observed concentration as a ratio of the median value observed in a normal pregnancy of the same gestation to obtain a multiple of the median (MoM), these gestational fluctuations are removed. The distributions of the MoM values in normal and Down pregnancies usually follow a Gaussian distribution when the MoM is log transformed; however, with all markers there is a significant overlap of the two populations but it is possible to establish from the Gaussian distributions, the likelihood of any one result coming from the population of results associated with fetal Down syndrome. An individual patient specific risk is then calculated by multiplying the a priori risk (usually based on maternal age [Cuckle et al., 1987] or previous aneuploid history [Nicolaides et al., 1999]) with the likelihood ratio. Unfortunately, no one individual marker alone has sufficient discriminatory power and a more efficient screening program can be achieved by combining information from more than one marker. The detailed mathematics of this multimarker approach is beyond the scope of this review but can be found in other publications [Reynolds and Penney, 1990]. A summary of the modeled expected screening performance using various marker combinations is shown in Table I.

In over 20 prospective intervention studies, the modeled second trimester screening performance has been confirmed in large-scale studies over a considerable time period [Spencer, 1999; Cuckle, 2000; Muller et al., 2002b; Wald et al., 2003a].

Questions are still being raised over the value of the fourth major second trimester marker Inhibin A. Inhibin is a dimer composed of an alpha subunit and one of two similar but distinguishable beta subunits. The earlier assays for inhibin were non-specific and measured all forms of inhibin containing the alpha subunit [van Lith et al., 1992; Spencer et al., 1993a]. More specific assays allowing the measurement of dimeric inhibin A were developed, and studies have shown this to be a useful second trimester marker were levels are increased in trisomy 21 [Aitken et al., 1996; Malone et al., 2005a]. There is a large

TABLE I. Modeled Expected Detection Rates for Down Syndrome at a 5\% False Positive Rate Using a Variety of Combinations of Second Trimester Biochemical Markers [Cuckle, 2001]

Marker combination Detection rate $(\%)$

AFP, free $\beta-\mathrm{hCG}$

63.2

AFP, free $\beta$-hCG, unconjugated estriol

66.8

AFP, free $\beta-h C G$, unconjugated estriol, inhibin $A$

72.1 correlation with inhibin A and hCG; this coupled with an assay methodology that is still evolving [Wallace et al., 1998], variable standardization, lack of a stable and robust commercially developed assays [Erickson et al., 2004; Harrison and Goldie, 2006], and poor center to center comparibility [Sturgeon et al., 2006] still remains an issue. While used across the United States, the UK National Screening Committee, based on a performance study, has recently made a statement suggesting that Inhibin A should not be used as part of a program for mass population screening (Muir Gray 2005, personal communication).

Apart from Down syndrome, the only other major aneuploidy that is routinely screened for in some second trimester screening programs is Edwards syndrome (trisomy 18). In all other regards, the biochemical patterns observed with the other aneuploidies are unremarkable-perhaps with the exception of Triploidy Type I and II, which may reflect placental pathology seen in this circumstance, particularly in type I (Table II)

For trisomy 18, protocols using AFP and Free Beta hCG predict a 50\% detection rate at a $1 \%$ false positive rate [Spencer et al., 1993c], while those using AFP, total hCG and unconjugated estriol (UE3) [Barkai et al., 1993; Palomaki et al., 1995] predict a $60 \%$ detection at a $0.3 \%$ detection. More recently, measurement of Pregnancy Associated Plasma Protein-A (PAPP-A) has been shown to potentially increase second trimester detection rates for trisomy 18 to some $82 \%$ for a $0.1 \%$ false positive rate using a two-step screening protocol [Spencer et al., 1999a; Muller et al., 2002a]. Prospective screening practice, in very large-scale studies, does seem to also support the model predictions for detection of trisomy 18 in the second trimester [Meier et al., 2003].

The past decade has seen a considerable focus on moving screening earlier into the first trimester. Earlier screening is anticipated to provide women with an earlier reassurance and if termination of pregnancy is required, this can often be completed before fetal movements are evident. 
TABLE II. Second Trimester Marker Patterns in Common Aneuploidies

\begin{tabular}{llll}
\hline Anomaly & \multicolumn{1}{c}{ AFP } & HCG & Inhibin A \\
\hline T21 & Low & High & High \\
T18 & Low & Low & Small decrease \\
T13 & Small increase & Normal & Normal \\
Turner & Small decrease. & High/low \pm hydrops & High/low \pm hydrops \\
Other sex & Normal or high & Normal or high & Normal decrease \\
Triploidy I & High & High & \\
Triploidy II & Normal & Low & \\
\hline
\end{tabular}

\section{The past decade has seen a} considerable focus on moving screening earlier into the first trimester. Earlier screening is anticipated to provide women with an earlier reassurance and if termination of pregnancy is required this can often be completed before fetal movements are evident.

Also termination of pregnancy in the first trimester is safer than later in pregnancy [Lawson et al., 1994]. The fact that some aneuploid pregnancies detected in the first trimester will be spontaneously lost before term is not a valid argument against early screening. For these women, it is important information to know with regard to future reproductive decisions and furthermore, a late miscarriage can be prevented.

A range of maternal serum biochemical markers have been investigated in both the first and second trimester of pregnancy in normal and chromosomally abnormal pregnancies. Table III summarizes a meta-analysis of published cases with trisomies 13, 18, and 21 in the first trimester. For trisomy 21, of the markers of value in the second trimester, only the elevated free $\beta-\mathrm{hCG}$ is of any value in the first and second trimester, and is reduced in both trimesters when trisomy 18 is present. The only other biochemical marker of value is the lowered levels of PAPP-A seen in cases with trisomies 13, 18, and 21.

A guide to the scale of clinical effectiveness in discriminating normal pregnancies and those affected by trisomy 21 can be obtained using the Mahalanobis distance, calculated from:

$\left(\frac{\text { mean }[\text { unaffected }]-\text { mean }[\text { affected }]}{\mathrm{SD}[\text { unaffected }]}\right)^{2}$

where the mean and standard deviation (SD) are in the log domain. Table IV summarizes this clinical effectiveness scale and includes for comparison the ultrasound marker nuchal translucency (NT) thickness, which is the single most effective marker for fetal aneuploidy at the 11-14-week period.

\section{NT AS A SINGLE MARKER}

TABLE III. Meta Analysis of Published Maternal Serum Biochemical Markers in Cases With Trisomies 21, 18, and 13 in the First Trimester [Modified From Spencer, 2005]

\begin{tabular}{|c|c|c|c|c|c|c|}
\hline \multirow[b]{3}{*}{$\underline{\text { Serum marker }}$} & \multicolumn{2}{|c|}{ Trisomy 13} & \multicolumn{2}{|c|}{ Trisomy 18} & \multicolumn{2}{|c|}{ Trisomy 21} \\
\hline & Median & & Median & & Median & \\
\hline & MoM & $\mathrm{N}$ & MoM & $\mathrm{N}$ & MoM & $\mathrm{N}$ \\
\hline AFP & 0.92 & 42 & 0.91 & 53 & 0.80 & 611 \\
\hline Total hCG & 0.74 & 42 & 0.39 & 53 & 1.33 & 625 \\
\hline Unconjugated estriol & & & & & 0.71 & 210 \\
\hline Free $\beta$-hCG & 0.51 & 45 & 0.27 & 126 & 1.98 & 846 \\
\hline Inhibin A & 0.74 & 45 & 1.41 & 235 & 1.59 & 112 \\
\hline Free $\alpha-\mathrm{hCG}$ & & & & & 1.00 & 163 \\
\hline CA125 & & & & & 1.14 & 34 \\
\hline PAPP-A & 0.25 & 42 & 0.20 & 119 & 0.45 & 777 \\
\hline SP1 & & & & & 0.86 & 246 \\
\hline Activin & & & 1.23 & 45 & 1.36 & 45 \\
\hline
\end{tabular}

There is now a considerable body of evidence in the literature to show that

\begin{tabular}{|c|c|}
\hline \multicolumn{2}{|c|}{$\begin{array}{l}\text { TABLE IV. Relative Clinical } \\
\text { Effectiveness (Mahalanobis } \\
\text { Distance) of Markers in } \\
\text { Discriminating for Trisomy } 21 \\
\text { in the First Trimester }\end{array}$} \\
\hline Marker & $\begin{array}{c}\text { Mahalanobis } \\
\text { distance }\end{array}$ \\
\hline NT & 11.00 \\
\hline PAPP-A & 2.48 \\
\hline Free $\beta$-hCG & 1.74 \\
\hline Total/intact hCG & 0.27 \\
\hline
\end{tabular}


when NT is measured in a defined way by sonographers and obstetricians who have taken part in a program of training and ongoing audit, that in combination with maternal age detection rates of $70-$ $75 \%$ are achievable in routine practice for a false positive rate of $5 \%$ or less for trisomy 21 and similarly for trisomy 13 and 18 [Nicolaides, 2004]. In fact, increased NT has been shown to be a feature of a whole variety of chromosomal anomalies and genetic syndromes [Souka et al., 2001; Nicolaides, 2003]. Snijders et al. [1998] remains the seminal work establishing the credibility of the use of NT in a multicenter setting.

\section{BIOCHEMICAL MARKERS}

When used as a single marker in combination with maternal age, at a fixed $5 \%$ false positive rate, the best estimates for detection of cases with trisomy 21 range from 42 to $46 \%$ for free $\beta$-hCG [Cuckle and van Lith, 1999; Spencer et al., 1999b] and 48 to 52\% for PAPP-A [Cuckle and van Lith, 1999; Spencer et al., 1999b] for specimens collected between the 10- and 14-week period. When the two markers are combined together with maternal age, the detection rates increase to $67 \%$ [Spencer et al., 1999b]. When comparing detection rates between different time periods in pregnancy, it is important to make allowance for the inherent lethality of fetal aneuploidy. Hence, an observed detection rate of $75 \%$ in the first trimester is actually worse than the same detection rate in the second trimester. Dunstan and Nix [1998] have provided a methodology to make this comparison taking into account fetal loss for trisomy 21. If one assumes the fetal loss in women of all ages is best described in the studies of Morris et al. [1999], a predicted detection rate at the time of the test of $75 \%$ in the second trimester would need to be $3.5 \%$ higher in the first trimester for it to be statistically significantly higher [Spencer, 2001c]. In practice, such detection rates of around $80 \%$ cannot be achieved by first trimester serum biochemistry or by fetal NT alone, but can be achieved by combing the two.

\section{COMBINED ULTRASOUND AND BIOCHEMICAL SCREENING}

Combining maternal serum biochemistry and NT measurement in the first trimester is an effective screening procedure because the two modalities do not appear to be correlated [Spencer et al., 1999b]. A retrospective study of 210 cases of trisomy 21 and approximately 1,000 controls showed that this combined approach could achieve $89 \%$ detection for a $5 \%$ false positive rate [Spencer et al., 1999b]. Other studies [Wald and Hackshaw, 1997; Cuckle and van Lith, 1999; De Graff et al., 1999] have also found that such a combination can achieve detection rates in excess of $80 \%$. In addition to identifying cases with trisomy 21 , combined screening has also been shown to identify pregnancies complicated by trisomy 13 [Spencer et al., 2000c], trisomy 18 [Tul et al., 1999], Turner syndrome and other sex aneuploidies [Spencer et al., 2000b], and Triploidy Type I and II [Spencer et al., 2000d]. In addition to detecting $89 \%$ of cases with trisomy 21 , it has been estimated that $90 \%$ of other chromosomal anomalies can be identified for an additional $1 \%$ false positive rate.

Table V summarizes the basic pattern of changes in the various markers associated with the various aneuploidies. It can be seen that from a marker perspective, just using NT and maternal serum biochemistry, it is impossible to distinguish a clear discriminatory pattern between trisomy 13 and trisomy 18 . This has led to the development of a combined trisomy 13/18-risk algorithm being used in routine practice [Spencer and Nicolaides, 2002]. The observation that fetal heart rate is also altered in a number of chromosomal anomalies [Liao et al., 2000; Papageorghio et al., 2006] may lead in the future to separate algorithms identifying specifically risk for trisomy 13 and trisomy 18 .

In prospective screening using the combined approach, the modeled detection rates have been largely confirmed in quite larger series (see Table VI). Combined screening in the first trimester can be delivered in different ways. One example would be the contemporaneous approach taken in the OSCAR clinics [Spencer, 1998; Spencer et al., 2000e, 2003b; Bindra et al., 2002; Avgidou et al., 2005; Nicolaides et al., 2005], where the ultrasound examination and the biochemical testing are performed simultaneously and the combined risk provided in the one stop clinic. The benefits of this type of approach in being able to deliver face to face counseling have been outlined [Spencer, 2002, 2004]. Another approach is that of concurrent testing. In the more common variant of this model, the patient undergoes the ultrasound examination and blood, NT and clinical data are sent to a reference laboratory and the combined risk report returned to the obstetrician a couple of days later for patient counseling to occur [Stenhouse et al., 2004]. A further variant is sequential testing when the blood sample is taken a few days prior to the ultrasound examination so that the biochemical concentration results are
TABLE V. First Trimester Biochemical and Ultrasound Marker Patterns in Various Aneuploides

\begin{tabular}{lccccc}
\hline & $\mathrm{NT}$ & $\mathrm{CRL}$ & FHR & Free $\beta$-hCG & PAPP-A \\
\hline Trisomy 21 & $\uparrow 2.5$ & $\leftrightarrow$ & $\uparrow$ & $\uparrow 2.2$ & $\downarrow 0.5$ \\
Trisomy 18 & $\uparrow 3.5$ & $\downarrow$ & $\downarrow$ & $\downarrow 0.3$ & $\downarrow 0.5$ \\
Trisomy 13 & $\uparrow 2.5$ & $\leftrightarrow$ & $\uparrow$ & $\downarrow 0.5$ & $\downarrow 0.3$ \\
Turner's & $\uparrow 7.0$ & $\leftrightarrow$ & $\uparrow$ & $\leftrightarrow$ & $\downarrow 0.5$ \\
Triploidy I & $\uparrow 2.5$ & $\leftrightarrow$ & $\downarrow$ & $\uparrow 8.0$ & $\downarrow 0.8$ \\
Triploidy II & $\leftrightarrow$ & $\downarrow$ & $\downarrow$ & $\downarrow 0.2$ & $\downarrow 0.1$ \\
\hline
\end{tabular}


TABLE VI. Summary of Results From Major First Trimester Combined Prospective Screening Programs

\begin{tabular}{llrrrr}
\hline Study & Design & Size & No T21 & DR\% & FPR\% \\
\hline Spencer et al. [1999b] & R & 1,000 & 210 & 89.0 & 5.0 \\
Nicolaides et al. [2005] & P/I & 75,821 & 325 & 92.6 & 5.2 \\
Krantz et al. [2000] & P/I & 5,809 & 33 & 90.9 & 7.9 \\
Crossley et al. [2002] & P/NI & 17,230 & 34 & 82.0 & 5.0 \\
Schuchter et al. [2002] & P/I & 4,939 & 14 & 85.7 & 5.0 \\
Von Kaisenberg et al. [2002] & P/I & 3,864 & 19 & 84.2 & 6.6 \\
Muller et al. [2003b] & P/NI & 5,694 & 26 & 73.0 & 4.7 \\
Wald et al. [2003b] & P/NI & 325 & 65 & 85.0 & 6.1 \\
Wapner et al. [2003] & P/I & 8,514 & 61 & 78.7 & 5.0 \\
Stenhouse et al. [2004] & P/I & 4,974 & 15 & 93 & 5.9 \\
Hadlow et al. [2005] & P/I & 10,436 & 32 & 90.6 & 3.6 \\
Malone et al. [2005a] & P/NI & 38,167 & 117 & 87 & 5.0 \\
O'Leary et al. [2006] & P/I & 22,280 & 60 & 83 & 3.7 \\
Perni et al. [2006] & P/I & 4,615 & 22 & 90.9 & 5.0 \\
Total (P) & & 202,668 & 823 & 88 & 5.0 \\
\hline
\end{tabular}

$\mathrm{R}$, retrospective study; P, prospective study; I, interventional; NI, non-interventional 1st trimester but interventional 2 nd trimester.

available at this time and a combined risk can be calculated by the obstetrician and the patient counseled at this visit [Borrell et al., 2004]. In this later model, it may be possible to harness the slight improvement in detection by performing the biochemistry at 9-10 weeks. (See section on temporality).

\section{IMPROVING ACCURACY OF INDIVIDUAL RISKS-CO-VARIABLES}

Screening programs invariably quote population detection rates and false positive rates to clients when counseling women or in the literature made avail- able to women. Often little attention is focused on the individual, for example in second trimester screening detection rates of $75 \%$ may be achieved by the program at a $5 \%$ false positive rate, but these are in fact overall populationderived data which may not be specific for a given individual. In a 20-year-old, the detection rate is much less (around $45 \%$ ) and the false positive rate much lower (around 3\%), while in a 40-yearold, detection rates are higher (around $92 \%$ ) and false positive rates higher (around 40\%) [Reynolds et al., 1993]. Similarly in first trimester, screening detection rates fall to around $80 \%$ at 20 (false positive rates $2.5 \%$ ) and increase to $96 \%$ at 40 (false positive rate $25 \%$ ), thus preferably counseling information needs to be tailored to the individual [Spencer, 2001b]. In a similar way, other personal or individual factors may influence personal risk and these need to be taken into account when calculating individual risks. Although correcting for many of these factors (or co-variables) in themselves have little impact on detection rates at the population level, they can be quite significant for the individual. Examples of such factors which might be taken into account are summarized in Table VII. A more detailed descrip-

TABLE VII. Factors Influencing Maternal Serum Biochemical Markers Levels or Risk for Trisomy 21

\begin{tabular}{|c|c|c|}
\hline Co-variable & First trimester & Second trimester \\
\hline Gestational age & PAPP-A increased, free $\beta-\mathrm{hCG}$ decreased after 9 weeks & AFP, UE3 increased, hCG decreased, inhibin little change \\
\hline Maternal weight & All decreased with increasing weight & All decreased with increasing weight \\
\hline Multiple pregnancy & Twice higher in twins, three times higher in triplets & Twice higher in twins, three times higher in triplets \\
\hline IDDM & PAPP-A and free $\beta-h C G$ (?) decreased & $\begin{array}{l}\text { ? AFP decreased related to level of control, UE3 and } \\
\text { hCG decreased, ? inhibin }\end{array}$ \\
\hline Fetal sex & Free $\beta-\mathrm{hCG}$ and PAPP-A increased with female fetus & HCG increased and AFP decreased with female fetus \\
\hline Assisted conception & Free $\beta-\mathrm{hCG}$ increased, PAPP-A decreased & UE3 decreased, hCG increased \\
\hline Ethnicity & Afro-Caribbean and Asian both markers increased & $\begin{array}{l}\text { AFP, hCG increased in Asian and Afro-Caribbean, } \\
\text { inhibin lowered in Afro-Caribbean }\end{array}$ \\
\hline Smoking & PAPP-A decreased & $\begin{array}{l}\text { HCG, UE3 decreased, AFP increased and inhibin } \\
\text { very increased }\end{array}$ \\
\hline Gravidity/parity & $\begin{array}{l}\text { Both markers increased with increasing number of } \\
\text { pregnancies }\end{array}$ & HCG decreased with increasing pregnancies \\
\hline Vaginal bleeding & Unclear if any effect & AFP increased \\
\hline Previous pregnancy & $\begin{array}{l}\text { Two to three times more likely to be high risk if } \\
\text { high risk in a previous pregnancy }\end{array}$ & $\begin{array}{l}\text { Three to five times more likely to be high risk if high } \\
\text { risk in a previous pregnancy }\end{array}$ \\
\hline
\end{tabular}


tion of these can be found in Aitken et al. [2002].

\section{Screening in Twins}

Several complex issues are associated with screening for chromosomal anomalies in twin pregnancies [Spencer, 2005], namely: how to interpret the marker values, the paucity of data in abnormal affected pregnancies when the fetuses are either concordant or discordant for an anomaly, the dilemmas regarding which invasive test to offer, the perceived increase risk of such procedures in twins, the technical difficulties of ensuring fetal tissue is obtained from each fetus, the need to ensure each fetus can be clearly differentiated at a later date and, finally the difficulties of clinical management of fetal reduction and potential risk to the unaffected cotwin. These concerns form the basis of arguments that screening in twins poses such a serious clinical, ethical, and moral dilemma [Reynolds, 1995; Cuckle, 1998] that it should be discouraged [Wald et al., 1998]. Despite such reservations, screening programs for twin pregnancies have been successfully implemented in both the second and first trimesters, in units that have strong links with specialized fetal medicine centers [Spencer and Nicolaides, 2003].

The biochemical markers in twin pregnancies are on average twice that in normal singleton pregnancies. In a summary of the world literature, the median MoM PAPP-A in 707 cases was 1.826 and for free $\beta$-hCG was 2.035 from 825 cases [Spencer, 2005]. Wald et al. [1991] proposed a Pseudo-Risk approach for risk assessment in twins whereby the measured result (in MoM) is divided by the corresponding median MoM value found in twin pregnancies, and treating the risk calculation as for a singleton pregnancy. Although such an approach leads to lower detection rates in twins (compared to singleton pregnancies), it is though a valuable procedure in the second trimester [Muller et al., 2003a; Spencer, 2005]. In the first trimester, it is predicted that adding in twin biochemistry correction will improve the detection rate by NT alone from 75 to $80 \%$-some $10 \%$ less than achieved in singleton pregnancies [Spencer, 2000]. In prospective practice, this does seem to be achievable also [Spencer and Nicolaides, 2003]. However, the median MoM twin corrected free $\beta$-hCG was only 1.39 in 19 cases discordant for trisomy 21 whilst that for PAPP-A was 0.56 [Spencer, 2005]. When chorionicity or zygosity is considered, there does appear to be measurable differences in the marker levels, particularly for PAPP-A which appear $10 \%$ lower in monochorionic twins [Spencer, 2001a]. Further studies are needed to confirm these differences. It remains to be seen whether screening in twins in the first trimester is more widely accepted using ultrasound alone or ultrasound in combination with maternal serum biochemistry. Little data is available in higher order multiple pregnancies.

In the first trimester, NT measurements are not affected by the problems of dilutional effects encountered with serum only screening, and the ability to produce a fetus-specific risk have resulted in some authors arguing that first trimester ultrasound should be the method of choice for screening twins. However, a combination of the two does allow improved detection yet still retaining the benefits of using NT to identify the fetus at risk in the case of discordant twins. In practice, however, it has been concluded that NT should be the predominant factor by which women presenting with increased risk should be counseled regarding an invasive test [Spencer and Nicolaides, 2003].

\section{Temporal Variation}

It has become evident over time that many markers show a different pattern of variation in cases with aneuploidy across the first and second trimester. Berry et al. [1997] collected samples from 45 cases with trisomy 21 in the first trimester and in the second trimester. They showed that in these same patients, the first trimester free $\beta$-hCG median was 1.99 compared with 2.79 in the second trimester. Similarly for PAPP-A, the corresponding values were 0.50 and
$0.94 \mathrm{MoM}$. In the second trimester, Spencer and Macri [Macri et al., 1990, 1993; Spencer and Macri, 1992; Spencer et al., 1992, 1993b; Spencer, 1999] have demonstrated that median free $\beta-\mathrm{hCG}$ levels and detection rates for trisomy 21 are higher at around 14-16 weeks than at 17-19 weeks. A similar pattern was shown for free $\beta$-hCG in the first trimester when levels increased from 1.75 at 11 weeks to 2.25 at 13 weeks and for PAPP-A, the levels increased from 0.44 at 11 weeks to 0.69 at 13 weeks [Spencer et al., 1999b]. In a comprehensive analysis of data from between 700 and 1,000 cases with trisomy 21 and over 100,000 unaffected pregnancies Spencer et al. [2002, 2003a] have described in detail the temporal variation across the first and second trimester for the markers AFP, PAPP-A, free $\beta$ hCG, and total hCG. The result of this temporal variation is that the separation between normal pregnancies and those with trisomy 21 is changing all the time. Using such a variable separation model prevents significant errors in individual patient-specific risks when compared to a model where temporal change is not taken into account [Spencer et al., 2002, 2003a]. The other feature of such temporal variation is that for individual markers, there are key measuring periods. For example, PAPP-A is a better marker before 10 weeks but free $\beta$-hCG is a better marker at around 1214 weeks. The consequence of this opposing changing pattern is to some extent balanced so that detection rates across the 8-13 week window the variation is from $72.5 \%$ at 8 weeks to $62.6 \%$ at 13 weeks [Spencer et al., 2003a].

Temporal variation also exists for other aneuploidies. For example, in cases with trisomy 18, levels of PAPP-A are low in the 1 st trimester and get progressively lower throughout the 2 nd trimester. Indeed for trisomy 18, PAPP-A is probably the best clinical discriminator and a two-stage screening program has been proposed [Spencer et al., 1999a; Muller et al., 2002a]. In cases with trisomy 13, the low 1st trimester levels of free $\beta$-hCG [Spencer et al., 2000c] increase such that by the 18 th week, 
levels are elevated [Spencer et al., 2005].

Like free $\beta$-hCG, total or intact hCG also follows a temporal variation which is more pronounced than free $\beta$-hCG and which explains why free $\beta$-hCG may be a superior marker, particularly in the first trimester [Spencer et al., 2000a, 2003a].

\section{INTEGRATED TEST-SERUM INTEGRATED TEST}

An alternative to the combined first trimester screening approach has been proposed by Wald et al. [1999] based on multistage testing in the first and second trimester. The approach, termed "Integrated Screening" which is a form of Non-Disclosure Sequential Screening [Cuckle, 2002], has modeled the theoretical performance of a test which includes the measurement of NT and PAPP-A in the first trimester. A risk

\section{An alternative to the combined}

first trimester screening approach has been proposed by Wald et al. based on multistage testing in the first and second trimester. The approach, termed "Integrated Screening" which is a form of Non-Disclosure Sequential Screening, has modeled the theoretical performance of a test which includes the measurement of NT and PAPP- $A$ in the first trimester.

based on these parameters is not calculated (withheld from the patient) and further result for free $\beta$-hCG, AFP, unconjugated estriol, and inhibin are combined after the 16-18 week second trimester test. The theoretical detection rate predicted from such modeling suggests detection rates of $94 \%$ for a
$5 \%$ false positive rate or $85 \%$ at $1 \%$ false positive rate may be achievable. Although this modeled performance is a fraction higher than can be achieved routinely in the first trimester alone, the implementation of the integrated screening test as a method of population screening may be difficult in practice. First, it requires two visits by the patient at the appropriate timing with the consequent additional cost and inconvenience (and likelihood for default), second, women will have to wait to endure the additional anxiety associated with a 4-6 week wait for results when $90 \%$ of cases could be detected at the first visit and a first trimester termination offered. Additionally, some have seriously questioned the ethical and moral issues associated with withholding information after the first visit and others have questioned the validity of the statistical model used [Copel and Bahado-Singh, 1999; Reynolds et al., 1999; Down's Screening News, 2000; Herman et al., 2002; Chervenak et al., 2005].

Another possible alternative model proposed by Wald et al. [1999] involved a variation of the integrated test which excluded NT measurement. This option which became subsequently known as the Serum Integrated Test in modeling predicted an $85 \%$ detection rate at a $5 \%$ false positive rate or $66 \%$ at a $1 \%$ false positive rate.

\section{SURUSS AND FASTER TRIAL}

In 1996, the UK National Health Technology Assessment Program fund-

In 1996, the UK National

Health Technology Assessment Program funded a study to assess the comparative performance of first trimester versus second trimester screening-the Serum, Urine and Ultrasound Screening Study (SURUSS). ed a study to assess the comparative performance of first trimester versus second trimester screening - the Serum, Urine and Ultrasound Screening Study (SURUSS) [Wald et al., 2003a]. The study which measured NT (without any external QA process) and first and second trimester biochemical markers was based upon 47,053 singleton pregnancies and 101 cases with Down syndrome. The results of the study quoted detection rates of $85 \%$ at a $5 \%$ false positive rate for first trimester combined screening, $83 \%$ for second trimester Quadruple screening, and quoted detection rates of $93 \%$ for integrated and $86 \%$ for serum integrated.

Some have questioned the results from the SURUSS trial, particularly with respect to the quality and timing of the NT examinations. Of the 47,053 women recruited, $24 \%$ had either no NT or NT done at appropriate time; 9\% had NT done at inappropriate time; in $7 \%$, they were unable to obtain a measurement; in $8 \%$, the image was of undefined unacceptable quality. In addition, concern has been raised regarding the quality of the NT measurements. The standard and protocol for NT measurement was not published; neither was a description of training nor quality assessment made. Only 65\% of women had NT along with first and second trimester bloods making the study group 30,375 , with 65 cases of trisomy 21 . Actual biochemical analysis was only performed on the 65 T21 cases along with 5 controls matched for maternal age ( \pm 10 years), CRL ( $\pm 5 \mathrm{~mm})$, length of storage (18 months). Inhibin A data was significantly different to published data; therefore, they used population parameters from another study. In summary, all detection rates and false positive rates were modeled using all other population parameters from this one analysis of less than 400 samples.

The First and Second Trimester Evaluation of Risk (FASTER) trial was a similarly designed prospective intervention trial undertaken from 1999 to 2002 in the USA and which finally reported in late 2005 [Malone et al., 2005a]. Unlike 


\section{The First and Second Trimester Evaluation of Risk (FASTER) trial was a similarly designed prospective intervention trial undertaken from 1999 to 2002 in the USA and which finally reported in late 2005.}

the SURUSS study, there was training, and quality review of images and biochemical analysis was performed on the whole data set. Of the 38,033 women enrolled in the first trimester (92 with trisomy 21), 95\% had an NT measurement of which a further $2.6 \%$ were later excluded after review, 99.5\% had first trimester biochemistry with 95\% having both NT and first trimester biochemistry. Some $93 \%$ also had second trimester biochemistry with 33,546 (88\% including 87 with trisomy 21) having complete data for both first and second trimester. The data obtained for unconjugated estriol was unexpectedly low in the trisomy 21 cases $(0.61$ MoM v 0.72 world average), so in the modeling exercise for detection rates, the world series average value was used. For NT and maternal age, a detection rate of $68 \%$ for a $5 \%$ false positive rate was obtained-a little lower than expected from the world FMF series. For first trimester biochemistry and maternal age, a detection rate of $67 \%$ for a $5 \%$ false positive rate was obtained-almost identical to the world series. For combined first trimester, screening at detection rate of $85 \%$ for a $5 \%$ false positive rate was obtained $(72 \%$ at $1 \%)$. For the serum integrated test, the detection rate was $86 \%$ at $5 \%$ false positive rate $(70$ at $1 \%)$ and for the full integrated test, the detection rate was $95 \%$ for a $5 \%$ false positive rate $(87 \%$ at $1 \%)$. Quadruple screening in the second trimester gave a detection rate of $81 \%$ at a $5 \%$ false positive rate $(60 \%$ at $1 \%)$. This study with its superior design confirmed in the American population that screening in the first trimester is an acceptable clinical alternative to second trimester and should certainly be offered to women presenting early in pregnancy. Unlike SURUSS, women found to have septated cystic hygroma were excluded from biochemical testing in the FASTER trial and do not contribute to the detection rates [Malone et al., 2005b; Molina et al., 2006; Sonek et al., 2006].

\section{NEW ULTRASOUND MARKERS}

Further improvements in screening performance-with either increased detection or lowered false positive rates may be achievable in the future by considering some relatively new first trimester ultrasound markers. Three markers in particular do seem to hold promise. The observation that the nasal bone appears absent in about $68 \%$ of fetuses with Down syndrome whilst being absent in only $1-2 \%$ of unaffected pregnancies [Cicero et al., 2001, 2003a] and that despite some association with increased NT and altered incidence in Afro-Caribbean populations [Cicero et al., 2004], the lack of correlation with biochemical markers is likely to result in detection rates of $96 \%$ at a $5 \%$ false positive rate or $90 \%$ at a $1 \%$ false positive rate [Cicero et al., 2003b, 2005]. This modeled detection rate has been achieved in prospective screening practice [Cicero et al., 2006].

The second potential marker is that of tricuspid regurgitation determined by pulsed wave Doppler ultrasonography [Huggon et al., 2003; Faiola et al., 2005] which is present in around $8 \%$ of normal fetuses and $65 \%$ of those with trisomy 21. Despite some association with increased NT, in both trisomy 21 and chromosomally normal pregnancies, the levels of maternal serum-free $\beta-\mathrm{hCG}$ and PAPP-A have been shown to be independent of the presence or absence of tricuspid regurgitation. Thus, combing all three modalities would be expected to achieve a detection rate of $95 \%$ at a $5 \%$ false positive rate or $90 \%$ at a $2 \%$ false positive rate [Falcon et al., 2006].

The third potential marker is that of abnormal blood flow through the ductus venosus. By measuring the Pulsitility Index for veins, studies have shown detection rates of $65-75 \%$ for a $4-5 \%$ false positive rate [Borrell, 2004] which increased to $75-80 \%$ when NT was added. When serum biochemical markers measured at 10 weeks were also added, the modeled detection rate increased to $92 \%$ at a $5 \%$ false positive rate or $84 \%$ at a $1 \%$ false positive rate [Borrell et al., 2005].

One major drawback to the general use of each of these new ultrasound markers is that each is time consuming, requiring highly skilled operators with much experience, and therefore, it is unlikely that these assessments will be incorporated into the routine first trimester scan.

\section{A NEW BIOCHEMICAL MARKER-ADAM 12}

ADAM 12-S is the secreted form of $A$ Disintegrin And Metallprotease 12, a glycoprotein of the Metzcin family synthesized by the placenta and secreted through pregnancy. ADAM 12-S has a

\section{ADAM 12-S is the secreted form of $A$ Disintegrin And Metallprotease 12, a glycoprotein of the Metzcin family synthesized by the placenta and secreted through pregnancy.}

proteolytic function against insulin like growth factor binding proteins IGFBP-3 and IGFBP-5 and regulates the bioavailabilty and action of IGF-1 and II [Wewer et al., 2005]. Initial studies in a small series of maternal serum samples showed ADAM 12 to be reduced in first trimester cases with trisomy 21 [Laigaard et al., 2003] and in cases with trisomy 18 [Laigaard et al., 2005a] as well as in women developing pre-eclampsia [Laigaard et al., 2005b]. In a larger series of 218 cases with trisomy 21 [Laigaard et al., 2006b] and a similar large series of 


\section{Initial studies in a small series of maternal serum samples showed ADAM 12 to be reduced in first trimester cases with trisomy 21}

88 cases in the second trimester [Christiansen et al., 2006], it has been confirmed that first trimester levels of ADAM 12 are reduced and that the reduction is more pronounced in earlier gestation. Discrimination appears best around $8-10$ weeks, decreasing slightly to $12-14$ weeks and then as ADAM 12 levels increase in trisomy 21 discrimination improves yet again at around 16 weeks [Christiansen et al., 2006; Laigaard et al., 2006a]. Population modeling showed that a combination of ADAM 12 and PAPP-A measured at 8-9 weeks, combined with NT and free $\beta$-hCG measured at 12 weeks could achieve a detection rate of $97 \%$ at a $5 \%$ false positive rate or $89 \%$ at a $1 \%$ false positive rate [Laigaard et al., 2006b].

\section{CONTINGENT FIRST TRIMESTER SCREENING}

One of the major issues with the universal implementation of first trimester screening including NT is the question of access to suitably qualified sonographers and obstetricians able to perform NT measurement. There is ample evidence from the literature that NT measured badly by untrained and un-audited centers is actually impacting on detection rates. Others have also argued that compared with the cost of simple serological testing-an ultrasound examination is costly and not appropriate universally in some health economies. To explore ways of managing access and cost of NT measurement, a new approach has been proposed called Contingent Testing. The first model of this type was described by Christiansen and Larsen [2002]. In this model, a women with a very high risk, as determined by the serological tests would be offered an invasive test, those with a very low risk, as determined by the serological test would be reassured, and those in the intermediate risk group would be offered a subsequent NT examination and a new risk calculated from both sets of information (Serology and NT in combination with maternal age). Those with a risk higher than the chosen cut-off would be offered invasive testing whilst the others would be reassured. In this model using a 1:65 cut-off to identify those with high risk, 1:1,000 to identify those with low risk and offering NT examination to those with risks between 1:64 and 1:1,000 $(19.4 \%$ of the population), modeled detection rates were found to be only $6.5 \%$ lower than the combined test for all and the overall program cost would be reduced almost by half.
The general form of any contingent test can be described in Figure 1 based on the work of Wright et al. [2004].

Another example of a first trimester contingent approach using serological testing to select women for measurement of NT and free $\beta-\mathrm{hCG}$ is based on early biochemical screening at $8-$ 9 weeks using PAPP-A and the new marker ADAM 12. Laigaard et al. [2006b] using a cut-off of 1:65 to select women at high risk, 1:1,000 to select women at low risk and those in between going on to have NT and free $\beta$-hCG at 12 weeks (representing $5.6 \%$ of all pregnancies), have suggested that a detection rate of $92 \%$ could be achieved for a $1 \%$ false positive rate.

The second stage screening test in contingent screening can also be further second trimester serological testing.

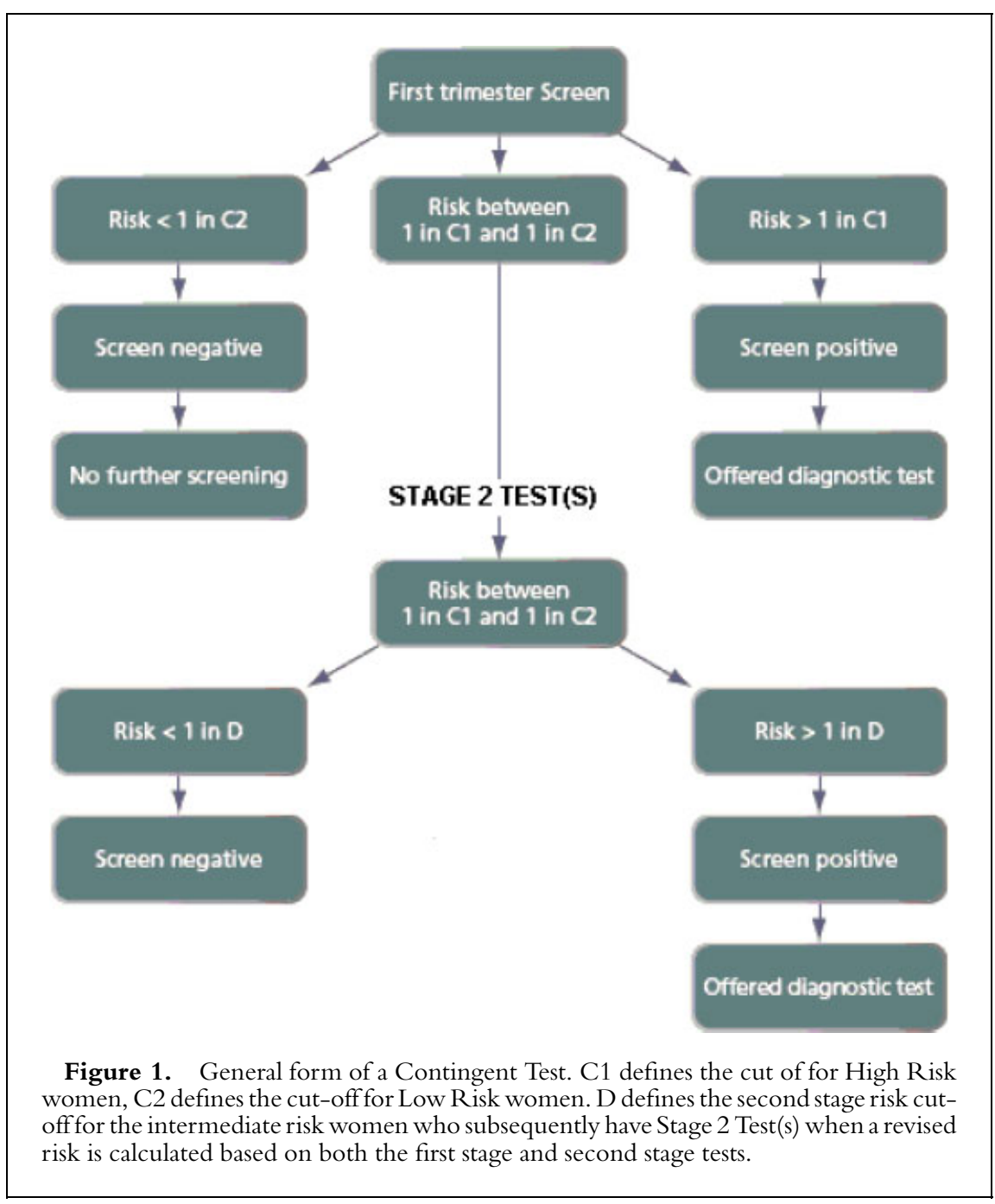


Maymon et al. [2004] chose a high first trimester risk cut-off (combined screening), above which a complete Integrated test is unlikely to become negative. Using this model, the high-risk group proceeds to invasive testing, while the low-risk group has no further testing and their screening is considered completed. The intermediate risk group proceeds to second trimester screening where the risk calculation takes into account the first trimester results. This model obviates the ethical, moral, and clinical implications of non-disclosure of the first trimester result and saves the financial implications of assessing the whole population with unnecessary second trimester tests. In a thorough analysis of the methodology of Contingent screening, Wright et al. [2004] showed how one could create models of screening programs using this approach in which the key deciding factors would be the proportion of cases detected in the first trimester and the proportion of women who would have completed the screening process in the first trimester. In a further follow-up article which looked at the development of separate protocols for the UK and USA to reflect the differences in commonly used tests, cutoffs, and gestational age at testing, Benn et al. [2005] showed clearly that for both countries, $60 \%$ of affected pregnancies would be detected in the first trimester and less than $20 \%$ of women would require a second trimester test with detection rates of $90 \%$ for a $2.5 \%$ false positive rate.

In yet a further extension of this concept which perhaps combines the approaches of Christiansen and Larsen [2002] and that of Wright et al. [2004], Wright et al. [2006a] have proposed a three-stage contingent protocol (Fig. 2). The first stage is based on measurement

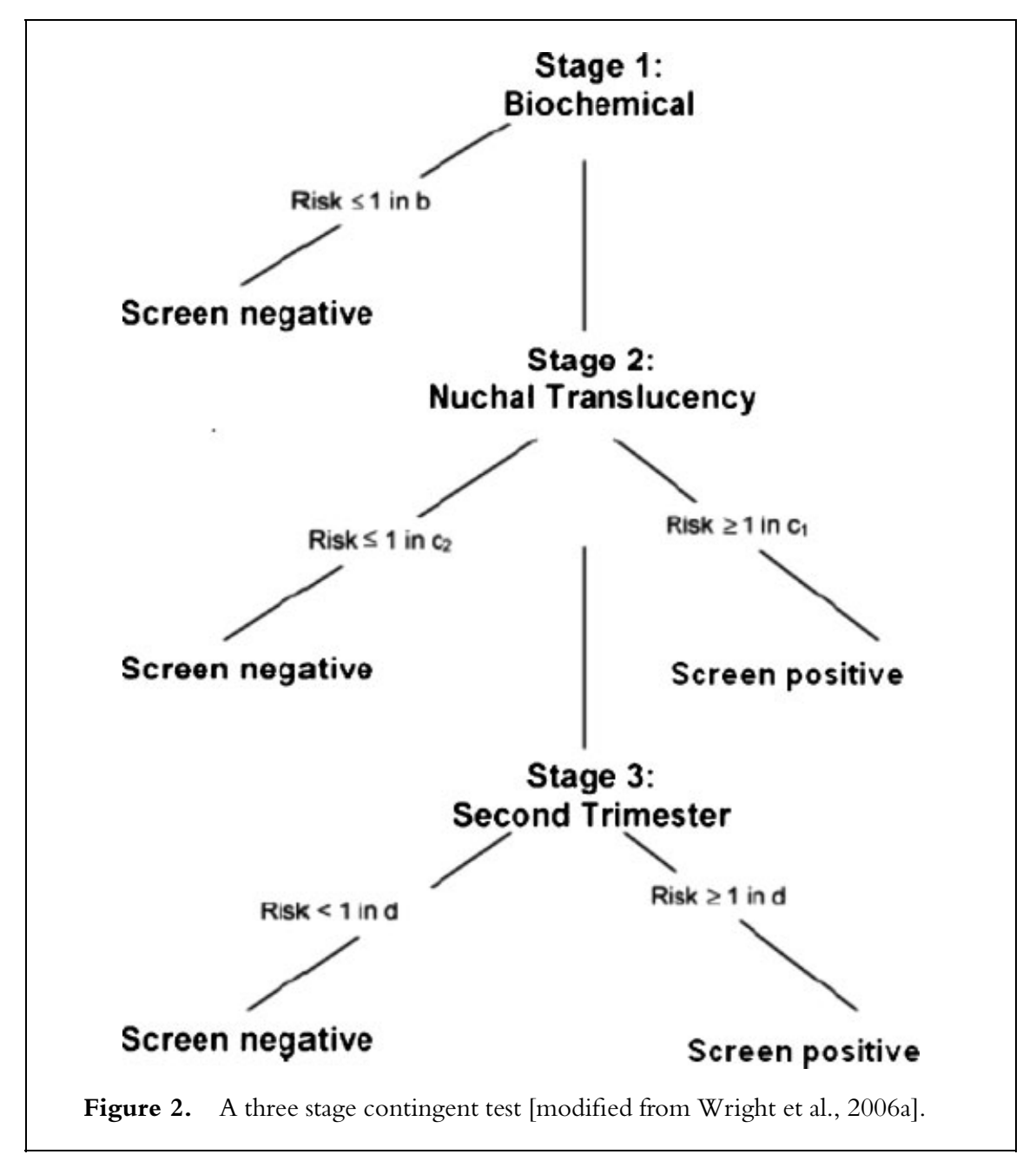

of PAPP-A and free $\beta$-hCG and a cut-off to select women who will proceed to have NT as the second stage and a combination risk calculated. Women with a low risk based on this initial cutoff will be reassured. At the second stage (NT measurement), a cut-off is used to select women at high risk who are offered invasive testing, while a low risk cut-off is used to identify low risk women who are reassured and those with intermediate risks then proceed to the third stage of second trimester serological marker testing with a risk based on all of the combined modalities. A single risk cut-off is then used to define those at low risk who are reassured and those at high risk who are offered invasive testing. In this model, if $40 \%$ of women are to proceed to stage 2 (NT) and $60 \%$ of screening is completed after stage 1 (PAPP-A and free $\beta-\mathrm{hCG}$ ) and $80 \%$ completed by the end of the first trimester-resulting in $20 \%$ requiring testing at stage 3 , for an $85 \%$ detection rate, the false positive rate would be $0.7 \%$ compared with $0.5 \%$ with the Integrated test.

Contingent screening clearly offer considerable psychological and clinical advantages over the Integrated test of early diagnosis, and if necessary, termination of pregnancy for the vast majority of cases. It offers early reassurance for a large number of women. Furthermore, it overcomes the difficulties for health care professionals imposed by the nondisclosure of early screening results. The added complexity (for health care professionals and women), however, needs consideration as does the need to have differing cut-offs at each stage and we need to assess the practicalities of such policies and the extent to which noncompliance will erode the performance (something which has never been assessed for the Integrated test).

A further variant of the Contingent test has been proposed by Nicolaides et al. [2005] in which the second stage test is a range of complex first trimester ultrasound examinations such as presence/absence of the nasal bone, presence/absence of tricuspid regurgitation or normal/abnormal Doppler velocity waveform in the ductus venosus, which 
could be performed after combined first trimester screening by referral to a tertiary fetal medicine center. In this model, detection rates would range from $92 \%$ at a $2.1 \%$ false positive rate with nasal bone, $94.2 \%$ at $2.7 \%$ for ductus venosus doppler, and $91.7 \%$ at $2.7 \%$ for tricuspid regurgitation. The application of absent nasal bone in such a strategy has been demonstrated in a recent prospective study [Cicero et al., 2006]. It is anticipated that a combination of all three procedures would lead to detection rates of $90 \%$ at a $1 \%$ false positive rate.

\section{REPEATED MEASURES SCREENING}

To add even further complexity to the array of screening programs that may be introduced in the future, a recent article [Wright and Bradbury, 2005] demonstrating the potential value of using highly correlated repeated measures of serum markers taken in the first and second trimesters flies against conventional thinking with respect to the choice of markers. The choice of markers in multi-marker screening tests has been influenced in the past by the extent to which they provide independent or new information as characterized by low correlations between markers and the univariate properties of markers. The perceived wisdom has been that combining markers with low correlations that individually have good discriminatory power represents the best approach. However, the work of Wright and Bradbury has demonstrated that certain combinations of highly corre- lated markers, some which individually have poor discriminatory power, have substantial benefits over the established combinations of markers used in the integrated test. For example, using the SURUSS parameters [Wald et al., 2003b], a repeat measure of PAPP-A alone at 10 weeks and at 16 weeks would result in a detection rate of $85 \%$ at a $2.3 \%$ false positive rate. Including unconjugated estriol in both trimesters would reduce the false positive rate to $0.5 \%$ and including NT at 12 weeks would reduce this further to $0.3 \%$. A similar effect is seen in the use of PAPP-A. Based on an $85 \%$ detection rate, the false positive rate decreases from $16 \%$ when PAPP-A is measured alone in the first trimester to $2.3 \%$ when measured in both trimesters. How can multiple measurements of a marker such as PAPP-A, that is so

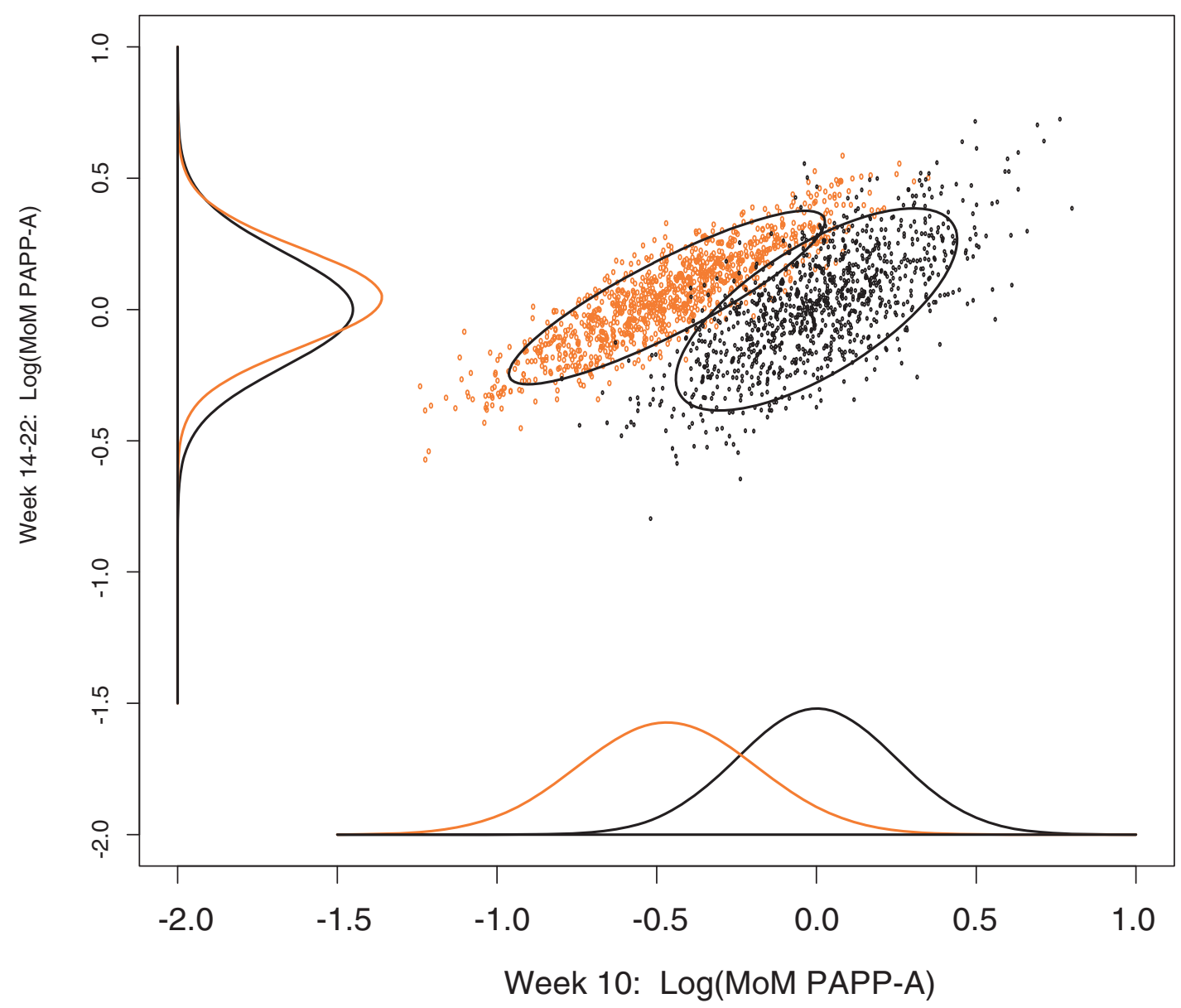

Figure 3. Bivariate distribution of $\log$ MoM PAPP-A in the first and second trimester. The red circles represent cases with Down syndrome and the black circles those with normal pregnancies. The ellipses represent contours containing $90 \%$ of the distribution. (Courtesy of David Wright). 
effective in the first trimester yet poor in the second trimester, be of such value in reducing the false positive rate? The mechanism is shown in Figure 3 which shows the distributions of PAPP-A MoM in both trimesters for the unaffected and affected populations. The figure clearly shows that even though the individual markers do not provide good discrimination, the joint distribution of the two is effective in separating the two populations.

Further studies need to be performed with other data sets other than the SURUSS parameters used in this modeling. One such recently published validation study [Palomaki et al., 2006] using repeat measures of PAPP-A in addition to the serum integrated test showed a detection rate of $86 \%$ for a $1 \%$ false positive rate compared with $82 \%$ using the serum integrated test alone. While some have tried to cast doubt on this approach [Wald et al., 2006], this approach appears to hold much promise [Wright et al., 2006b].

The pattern of successful markers that may be investigated in the future might include particularly those that are highly correlated between trimesters but also those in which the clinical discrimination is good in one trimester but is poor in another. An example is PAPP-A, inhibin, or total hCG, or alternatively where in Down syndrome a marker is low in one trimester and high in another as is SP1 [Qin et al., 1997] or ADAM 12 [Christiansen et al., 2006; Laigaard et al., 2006b]. Also repeat measures need not necessarily be restricted to cross trimesters. For example, a number of biochemical markers show temporal changes both within trimester and across trimester [Spencer et al., 2002, 2003a]. PAPP-A progressively loses clinical discrimination from 8 weeks onwards. Similarly, the discrimination with total hCG appears poor at 10 weeks but is maximal at 17 weeks, thus a repeat measures first trimester approach using PAPP-A and free $\beta$-hCG or total hCG with or without NT could achieve detection rates of $93 \%$ or $82 \%$ at a $1 \%$ false positive rate but performance would critically depend on the timing of the repeat measures [Wright et al., 2006c]. Further studies are needed to evaluate this approach with other markers.

\section{CONCLUSIONS}

In the past decade, prenatal screening for Down syndrome has become much more complicated as we strive to improve detection at lower false positive rates. Such research advances are coupled with a desire by women to have early screening and its attendant benefits such as early reassurance for most and the prospect of earlier, safer, and less psychologically traumatic termination when appropriate. With all of the different screening options (some only theoretical and some clearly implementable in practice), we must not lose sight of the fact that such complex strategies will need careful evaluation from a health care delivery aspect. Such complexity impacts directly on women's health care professionals, and there is concern regarding potential anxiety that such complicated programs and multiple options may present [Kornman et al., 1997; Mulvey and Wallace, 2000; Spencer and Aitken, 2004]. We also need to be more open in our thinking and less focused exclusively on the problem of Down syndrome. Many of the new models incorporating early ultrasound will also bring spin-offs in detection of other chromosomal and structural anomalies and the identification of women at high risk for many other potential problems of fetal-maternal health. High quality ultrasound will become the bed rock of early fetalmaternal assessment - as scientists and clinicians, we should embrace this and strive together with our imaging and fetal medicine colleagues to make a brighter safer and healthier future for the generations to come.

\section{REFERENCES}

Aitken DA, Wallace EM, Crossley JA, Swanston IA, van Pareren Y, van Maarle M, Groome NP, Macri JN, Connor JM. 1996. Dimeric Inhibin A as a marker for Down's syndrome in early pregnancy. $\mathrm{N}$ Engl $\mathrm{J}$ Med 334: 1231-1236.

Aitken DA, Crossley JA, Spencer K. 2002. Prenatal screening for neural tube defects and aneuploidy. In: Rimoin DL, Connor JM, Pyeritz RE, Korf BR, editors. Emery \& Rimoin's Principles and Practice of Medical Genetics, Vol. 1. London: Churchill Livingstone. p 763-801.

Avgidou K, Papageorghiou A, Bindra R, Spencer K, Nicolaides KH. 2005. Prospective first trimester screening for trisomy 21 in 30,564 pregnancies. Am J Obstet Gynecol 192: 1761-1767.

Barkai G, Goldman B, Ries L, Chaki R, Zer T, Cuckle H. 1993. Expanding multiple marker screening for Down's syndrome to include Edwards syndrome. Prenat Diagn 13:843-850.

Benn P, Wright D, Cuckle H. 2005. Practical strategies in contingent sequential screening for Down syndrome. Prenat Diagn 25:645652.

Berry E, Aitken DA, Crossley JA, Macri JN, Connor JM. 1997. Screening for Down's syndrome: Changes in marker levels and detection rates between first and second trimester. Br J Obstet Gynaecol 104:811817.

Bindra R, Heath V, Liao A, Spencer K, Nicolaides KH. 2002. One stop clinic for assessment of risk for trisomy 21 at 11-14 weeks: A prospective study of 15,030 pregnancies. Ultrasound Obstet Gynecol 20:219-225.

Borrell A. 2004. The ductus venosus in early pregnancy and congenital anomalies. Prenat Diagn 24:688-692.

Borrell A, Casals E, Fortuny A, Farre MT, Gonce A, Sanchez A, Soler A, Cararach V, Vanrell JA. 2004. First trimester screening for trisomy 21 combining biochemistry and ultrasound at individual optimal gestational ages. An interventional study. Prenat Diagn 24:541-545.

Borrell A, Gonce A, Martinez JM, Borobio V, Fortuny A, Coll O, Cuckle H. 2005. First trimester screening for Down syndrome with ductus venosus Doppler studies in addition to nuchal translucency and serum markers. Prenat Diagn 25:901-905.

Chervenak FA, McCullough LB, Chasen ST. 2005. Clinical implications of the ethics of informed consent for first trimester risk assessment for trisomy 21. Semin Perinatol 29:277-279.

Christiansen M, Larsen SO. 2002. An increase in cost-effectiveness of first trimester maternal screening programmes for fetal chromosome anomalies is obtained by contingent testing. Prenat Diagn 22:482-486.

Christiansen M, Spencer K, Laigaard J, Cowans NJ, Larsen SO, Wewer U. 2007. ADAM12 as a second trimester maternal serum marker in screening for Down's syndrome. Prenat Diagn 27 (in press).

Cicero S, Curcio P, Papageorghiou A, Sonek J, Nicolaides KH. 2001. Absence of nasal bone in fetuses with trisomy 21 at 11-14 weeks of gestation: An observational study. Lancet 358:1665-1667.

Cicero S, Longo D, Rembouskos G, Sacchini C, Nicolaides KH. 2003a. Absent nasal bone at 11-14 weeks of gestation and chromosomal defects. Ultrasound Obstet Gynecol 22:3135.

Cicero S, Bindra R, Rembouskos G, Spencer K, Nicolaides KH. 2003b. Integrated ultrasound and biochemical screening for tris- 
omy 21 at 11-14 weeks. Prenat Diagn 23: $306-310$.

Cicero S, Rembouskos G, Vandecruys H, Hogg M, Nicolaides KH. 2004. Likelihood ratio for trisomy 21 in fetuses with absent nasal bone at the 11-14 weeks scan. Ultrasound Obstet Gynecol 23:218-223.

Cicero S, Spencer K, Avgidou K, Faiola S, Nicolaides KH. 2005. Maternal serum biochemistry at 11-13+6 weeks in relation to the presence or absence of the fetal nasal bone on ultrasonography in chromosomally abnormal fetuses: An updated analysis of integrated ultrasound and biochemical screening. Prenat Diagn 25:977-983.

Cicero S, Avgidou K, Rembouskos G, Kagan KO, Nicolaides KH. 2006. Nasal bone in first trimester screening for trisomy 21. Am J Obstet Gynecol 195:109-114.

Copel JA, Bahado-Singh RO. 1999. Performing screening for Down's syndrome-A search for the family's values. $N$ Engl J Med 341: 521-522.

Crossley JA, Aitken DA, Cameron AD, McBride E, Connor JM. 2002. Combined ultrasound and biochemical (CUB) screening for Down's syndrome in the first trimester: A Scottish multicentre study. Br J Obstet Gynaecol 109:667-676.

Cuckle H. 1998. Down's syndrome screening in twins. J Med Screen 5:3-4.

Cuckle H. 2000. Biochemical screening for Down syndrome. Eur J Obstet Gynaecol Reprod Biol 92:97-101.

Cuckle H. 2001. Time for total shift to first trimester Down's screening. Lancet 358: 1658-1659.

Cuckle HS. 2002. Growing complexity in the choice of Down's syndrome screening policy. Ultasound Obstet Gynecol 19:323326.

Cuckle HS, van Lith JMM. 1999. Appropriate biochemical parameters in first trimester screening for Down syndrome. Prenat Diagn 19:505-512.

Cuckle HS, Wald NJ, Thomson SG. 1987. Estimating a woman's risk of having a pregnancy associated with Down's syndrome using her age and serum alphafetoprotein level. Br J Obstet Gynaecol 94:387402.

De Graff IM, Pajkrt E, Bilardo CM, Leschot NJ, Cuckle HS, Van Lith JM. 1999. Early pregnancy screening of fetal aneuploidy with serum markers and nuchal translucency. Prenat Diagn 19:458-462.

Down's Screening News. 2000. Integrated test replies to a survey. Down's Screening News 7:28-29.

Dunstan FDJ, Nix ABJ. 1998. Screening for Down's syndrome: The effect of test date on the detection rate. Ann Clin Biochem 35: 57-61

Egan JF, Benn P, Borgida AF, Rodis JF, Campbell WA, Vintzileos AM. 2000. Efficacy of screening for fetal Down syndrome in the United States from 1974 to 1997. Obstet Gynecol 96:979-985.

Erickson JA, Ashwood ER, Gin CA. 2004. Evaluation of a dimeric inhibin-A assay for assessing fetal Down syndrome: Establishment, comparison, and monitoring of median concentrations for normal pregnancies. Arch Pathol Lab Med 128:415-420.
Faiola S, Tsoi E, Huggon IC, Allan LD, Nicolaides KH. 2005. Likelihood ratio for trisomy 21 in fetuses with tricuspid regurgitation at the 11 to $13+6$ week scan. Ultrasound Obstet Gynecol 26:22-27.

Falcon O, Auer M, Gerovassili A, Spencer K, Nicolaides KH. 2006. Screening for trisomy 21 by fetal tricuspid regurgitation, nuchal translucency and maternal serum free $\beta$ hCG and PAPP-A at $11+0$ to $13+6$ weeks. Ultrasound Obstet Gynecol 27: $151-155$.

Hadlow N, Hewitt BG, Dickinson JE, Jacoby P, Bower C. 2005. Community based screening for Down's Syndrome in the first trimester using ultrasound and maternal serum biochemistry. BJOG 112:15611564.

Harrison G, Goldie D. 2006. Second-trimester Down's syndrome serum screening: Double, triple or quadruple marker testing? Ann Clin Biochem 43:67-72

Herman A, Dreazen E, Tovbin J, Weinraub Z, Bukovsky Y, Maymon R. 2002. Comparison between disclosure and non-disclosure approaches for trisomy 21 screening tests. Hum Reprod 17:1358-1362.

Hook EB. 1992. Prevalence, risks and recurrence. In: Brock DJH, Rodeck CH, FergusonSmith MA, editors. Prenatal Diagnosis and Screening. Edinburgh: Churchill Livingstone. p 351-392.

Huggon IC, DeFigueiredo DB, Allan LD. 2003. Tricuspid regurgitation in the diagnosis of chromosomal anomalies in the fetus at 1114 weeks. Heart 89:1071-1073.

Kornman LH, Wortelboer MJM, Beekhuis JR, Morssink LP. 1997. Mantingh A. Women's opinions and the implications of first-versus second trimester screening for fetal Down's Syndrome. Prenat Diagn 17:1011-1018.

Krantz DA, Hallahan TW, Orlandi F, Buchanan P, Larsen JW, Macri JN. 2000. First trimester Down syndrome screening using dried blood biochemistry and nuchal translucency. Obstet Gynecol 96:207-213.

Laigaard J, Sorensen T, Frohlich C, Pedersen BN, Christiansen M, Schiott K, Uldbjerg N Albrechtsen R, Clausen HV, Ottesen B, Wewer UM. 2003. ADAM12: A novel firsttrimester maternal serum marker for Down syndrome. Prenat Diagn 23:1086-1091.

Laigaard J, Christiansen M, Frohlich C, Pedersen BN, Ottesen B, Wewer UM. 2005a. The level of ADAM12 in maternal serum is an early first-trimester marker of fetal trisomy 18. Prenat Diagn 25:45-46

Laigaard J, Sorensen T, Placing S, Holck P, Frohlich C, Wojdemann KR, Sundberg K, Shalmi AC, Tabor A, Norgaard-Pedersen B, Ottesen B, Christiansen M, Wewer UM. 2005b. Reduction of the disintegrin and metalloprotease ADAM12 in preeclampsia. Obstet Gynecol 106:144-149.

Laigaard J, Cuckle H, Wewer UM, Christiansen M. 2006a. Maternal serum ADAM12 levels in Down's and Edwards' syndrome pregnancies at 9-12 weeks gestation. Prenat Diagn 26:689-691

Laigaard J, Spencer K, Christiansen M, Cowans NJ, Larsen SO, Pedersen BN, Wewer UM. 2006b. ADAM12 as a first trimester maternal serum marker in screening for Down's syndrome. Prenat Diagn 26:973-979.
Lawson HW, Frye A, Atrash HK, Smith JC, Shilman HB, Ramick M. 1994. Abortion mortality, United States, 1972-1987. Am J Obstet Gynecol 171:1365-1372.

Liao AW, Snijders R, Geerts L, Spencer K, Nicolaides KH. 2000. Fetal heart rate in chromosomally abnormal fetuses. Ultrasound Obstet Gynecol 16:610-613.

Macri JN, Kasturi RV, Krantz DA, Cook EJ, Moore ND, Young JA, Romero K, Larsen JW. 1990. Maternal serum Down syndrome screening: Free beta protein is a more effective marker than human chorionic gonadotropin. Am J Obstet Gynecol 163:1248-1253

Macri JN, Spencer K, Aitken DA, Garver K, Buchanan PD, Muller F, Boue A. 1993. First trimester free beta (hCG) screening for Down syndrome. Prenat Diagn 13:557562.

Malone FD, Canick JA, Ball RH, Nyberg DA, Comstock $\mathrm{CH}$, Bukowski R, Berkowitz RL, Gross SJ, Dugoff L, Craigo SD, TimorTritsch IE, Carr S, Wolfe HM, Dukes K, Bianchi DW, Rudnicka AR, Hackshaw AK, Lambert-Messerlian G, Wald NJ, D'Alton ME. 2005a. for the first trimester and second trimester evaluation of risk (FASTER) research consortium. $\mathrm{N}$ Engl J Med 353:2001-2011.

Malone FD, Ball RH, Nyberg DA, Comstock $\mathrm{CH}$, Berkowitz RL, Gross SJ, Dugoff L, Craigo SD, Timor-Tritsch IE, Carr SR, Wolfe HM, Dukes K, Canick J, Bianchi DW, D'Alton ME; 2005b. FASTER Trial Research Consortium. First trimester septated cystic hygroma: Prevalence, natural history and pediatric outcome. Obstet Gynecol 106:288-294.

Maymon R, Betser M, Dreazen E, Padoa A, Herman A. 2004. A model for disclosing the first trimester part of an integrated Down's syndrome screening test. Clin Genet 65:113-119.

Meier C, Huang T, Wyatt PR, Summers AM. 2003. Accuracy of trisomy 18 screening using the second-trimester triple test. Prenat Diag 23:443-446.

Molina FS, Avgidou K, Kagan KO, Poggi S, Nicolaides KH. 2006. Cystic hygromas, nuchal edema and nuchal translucency at 11-14 weeks of gestation. Obstet Gynecol 107:678-683

Morris JK, Wald NJ, Watt HC. 1999. Fetal loss in Down's syndrome pregnancies. Prenat Diagn 19:142-145.

Muller F, Sault C, Lemay C, Roussel-Mizon N, Forestier F, Frendo J-L, and the ABA Collaborative Group. 2002a. Second trimester two-step trisomy 18 screening using maternal serum markers. Prenat Diagn 22:605-608.

Muller F, Forestier F, Dingeon B, and the ABA Study Group. 2002b. Second trimester trisomy 21 maternal serum marker screening. Results of a country wide study of 854,902 patients. Prenat Diagn 22:925929 .

Muller F, Dreux S, Dupoizat H, Uzan S, Dubin M-F, Oury J-F, Dingeon B, Dommergues M. 2003a. Second trimester Down syndrome maternal serum screening in twin pregnancies: Impact of chorionicty. Prenat Diagn 23:331-335. 
Muller F, Benattar C, Audibert F, Roussel N, Dreux S, Cuckle H. 2003b. First trimester screening for Down Syndrome in France combining fetal nuchal translucency measurement and biochemical markers. Prenat Diagn 23:833-836.

Mulvey S, Wallace EM. 2000. Women's knowledge of and attitudes to first and second trimester screening for Down's syndrome. Br J Obstet Gynaecol 107:1302-1305.

Nicolaides KH. 2003. Screening for chromosomal defects. Ultrasound Obstet Gynecol 21: 313-321.

Nicolaides KH. 2004. Nuchal translucency and other first trimester sonographic markers of chromosomal abnormalities. Am J Obstet Gynecol 191:45-67.

Nicolaides KH, Sebire NJ, Snijders RJM. 1999. The 11-14 Weeks Scan. The Diagnosis of Fetal Abnormalities. London: Parthenon Publishing.

Nicolaides KH, Spencer K, Avgidou K, Faiola S, Falcon O. 2005. Multicentre study of first trimester screening for trisomy 21 in 75,821 pregnancies: Results and estimation of the potential impact of individual risk orientated two stage first trimester screening. Ultrasound Obstet Gynecol 25:221-226.

O'Leary P, Breheny N, Dickinson JE, Bower C, Goldblatt J, Hewitt B, Murch A, Stock R. 2006. First trimester combined screening for Down syndrome and other fetal anomalies. Obstet Gynecol 107:869-876.

Palomaki GE, Haddow JE, Knight GJ, Wald NJ, Kennard A, Canick JA, Saller DN, Blitzer MG, Dickerman LH, Fisher R, Hansmann D, Hansmann M, Luthy DA, Summers AM, Wyatt P. 1995. Risk based prenatal screening for trisomy 18 using alpha-fetoprotein, unconjugated estriol and human chorionic gonadotropin. Prenat Diagn 15:713723.

Palomaki GE, Wright DE, Summers AM, Neveux LM, Meier C, O'Donnell A, Huang T, Knight GJ, Haddow JE. 2006. Repeated measurement of pregnancy associated plasma protein-A (PAPP-A) in Down syndrome screening: A validation study. Prenat Diagn 26:730-739.

Papageorghiou AT, Avgidou K, Spencer K, Nix B, Nicolaides KH. 2006. Sonographic screening for trisomy 13 at 11 to $13(+6)$ weeks of gestation. Am J Obstet Gynecol 194:397-401

Perni SC, Predanic M, Kalish RB, Chervenak FA, Chasen ST. 2006. Clinical use of first trimester aneuploidy screening in a United States population can replicate data from clinical trials. Am J Obstet Gynecol 194: 127-130.

Qin QP, Christiansen M, Nguyen TH, Sorensen S, Larsen SO, Pedersen BN. 1997. Schwangerschaftsprotein 1 (SP1) as a maternal serum marker for Down syndrome in the first and second trimesters. Prenat Diagn 17: 101-108.

Reynolds TM. 1995. Down's syndrome screening in twin pregnancies. Prenat Diagn 15:386387.

Reynolds T, Penney M. 1990. The mathematical basis of multivariate risk analysis: With special reference to screening for Down syndrome associated pregnancy. Ann Clin Biochem 27:452-458.
Reynolds TM, Nix AB, Dunstan FD, Dawson AJ. 1993. Age-specific detection and false positive rates: An aid to counseling in Down's Syndrome risk screening. Obstet Gynecol 81:447-450.

Reynolds T, Zimmermann R, Wright E. 1999. Integrated screening for Down's Syndrome. N Engl J Med 341:1935.

Royal College of Obstetricians and Gynaecologists. 1997. Recommendations arising from the 32nd Study Group: Screening for Down syndrome in the first trimester. In: Grudzinskas JG, Ward RHT, editors. Screening for Down Syndrome in the First Trimester. London: RCOG Press. p 353-356.

Schuchter K, Hafner E, Stangl G, Metzenbaur M, Hefinger D, Philipp K. 2002. The first trimester 'combined test' for the detection of Down's syndrome pregnancies in 4939 unselected pregnancies. Prenat Diagn 22: 211-215

Snijders RJM, Sebire NJ, Nicolaides KH. 1995. Maternal age and gestational age specific risks for chromosomal defects. Fetal Diag Ther 10:356-357.

Snijders RJM, Noble P, Sebire N, Souka A, Nicolaides KH. 1998. UK multicentre project on assessment of risk of trisomy 21 by maternal age and fetal nuchal translucency thickness at 10-14 weeks of gestation. Lancet 351:343-346.

Sonek J, Croom C, McKenna D, Neiger R. 2006. First trimester septated cystic hygroma: Prevalence, natural history and pediatric outcome. Obstet Gynecol 107:424.

Souka AP, Krampl E, Bakalis S, Heath V, Nicolaides KH. 2001. Outcome of pregnancy in chromosomally normal fetuses with increased nuchal translucency in the first trimester. Ultrasound Obstet Gynecol 18:9-17.

Spencer K. 1998. Near patient testing and Down's syndrome screening. Proc UKNEQAS 3:130.

Spencer K. 1999. Second trimester prenatal screening for Down's syndrome using alpha-fetoprotein and free beta hCG: A seven year review. Br J Obstet Gynaecol 106:1287-1293

Spencer K. 2000. Screening for trisomy 21 in twin pregnancies in the first trimester using free $\beta$-hCG and PAPP-A combined with fetal nuchal translucency thickness. Prenat Diagn 20:91-95.

Spencer K. 2001a. Screening for trisomy 21 in twin pregnancies in the first trimester: Does chorionicity impact on maternal serum free $\beta-\mathrm{hCG}$ or PAPP-A levels? Prenat Diagn 21:715-717.

Spencer K. 2001b. Age related detection and false positive rates when screening for Down's Syndrome in the first trimester using fetal nuchal translucency and maternal serum free $\beta$-hCG and PAPP-A. Br J Obstet Gynaecol 108:1043-1046

Spencer K. 2001c. What is the true fetal loss rate in pregnancies affected by trisomy 21 and how does this influence when first trimester detection rate are superior to those in the second trimester. Prenat Diagn 21:788789.

Spencer K. 2002. Point of care screening for chromosomal anomalies in the first trimester. Clin Chem 48:403-404.
Spencer K. 2004. Screening at the point of care: Down Syndrome-A case study. In: Price CP, St. John A, Hicks JM, editors. Point of Care Testing. Washington: AACC Press. p 333-339.

Spencer K. 2005. Non-invasive screening tests. In: Blickstein I, Keith L, editors. Multiple Pregnancy: Epidemiology, Gestation and Perinatal Outcome. London: Parthenon. Chapter 20.

Spencer K, Aitken D. 2004. Factors affecting women's preference for type of prenatal screening test for chromosomal anomalies. Ultrasound Obstet Gynecol 24:735-739.

Spencer K, Macri JN. 1992. Early detection of Down's syndrome using free beta human choriogonadotropin. Ann Clin Biochem 29:349-350.

Spencer K, Nicolaides KH. 2002. A first trimester trisomy $13 /$ trisomy 18 risk algorithm combining fetal nuchal translucency thickness, maternal serum free $\beta-\mathrm{hCG}$ and PAPP-A. Prenat Diagn 22:877-879.

Spencer K, Nicolaides KH. 2003. Screening for trisomy 21 in twins using first trimester ultrasound and maternal serum biochemistry in a one stop clinic: A review of three years experience. Br J Obstet Gynaecol 110: 276-280.

Spencer K, Coombes EJ, Mallard AS, Ward AM. 1992. Free beta human chorionic gonadotropin in Down syndrome screening: A multicentre study of its role compared with other biochemical markers. Ann Clin Biochem 29:506-518.

Spencer K, Wood PJ, Anthony FW. 1993a. Elevated levels of maternal serum inhibin immunoreactivity in second trimester pregnancies affected by Down's syndrome. Ann Clin Biochem 30:219-220.

Spencer K, Macri JN, Anderson RW, Aitken DA, Berry E, Crossley JA, Wood PJ, Coombes EJ, Stroud M, Worthington DJ, et al. 1993b. Dual analyte immunoassay in neural tube and Down's syndrome screening: Results of a multicentre clinical trial. Ann Clin Biochem 30:394-401.

Spencer K, Mallard AS, Coombes EJ, Macri JN. 1993c. Prenatal screening for trisomy 18 with free beta human chorionic gonadotrophin as a marker. BMJ 307:1455-1458.

Spencer K, Crossley JA, Green K, Worthington DJ, Brownbill K, Aitken DA. 1999a. Second trimester levels of pregnancy associated plasma protein-A in cases of trisomy 18 . Prenat Diagn 19:1127-1134.

Spencer K, Souter V, Tul N, Snijders R, Nicolaides KH. 1999b. A screening program for trisomy 21 at 10-14 weeks using fetal nuchal translucency, maternal serum free $\beta$ human chorionic gonadotropin and pregnancy-associated plasma protein-A. Ultrasound Obstet Gynecol 13:231-237.

Spencer K, Berry E, Crossley JA, Aitken DA, Nicolaides KH. 2000a. Is maternal serum total hCG a marker of trisomy 21 in the first trimester of pregnancy. Prenat Diagn 20: $311-317$

Spencer K, Tul N, Nicolaides KH. 2000b. Maternal serum free $\beta-h C G$ and PAPP-A in fetal sex chromosome defects in the first trimester. Prenat Diagn 20:390-394.

Spencer K, Ong C, Skentou H, Liao AW, Nicolaides KH. 2000c. Screening for 
Trisomy 13 by fetal nuchal translucency thickness and maternal serum free $\beta$-hCG and PAPP-A at 10-14 weeks. Prenat Diagn 20:411-416.

Spencer K, Liao AWJ, Skentou H, Cicero S, Nicolaides KH. 2000d. Screening for triploidy by fetal nuchal translucency and maternal serum free $\beta-\mathrm{hCG}$ and PAPP-A at $10-14$ weeks of gestation. Prenat Diagn 20:852-853

Spencer K, Spencer CE, Power M, Moakes A, Nicolaides KH. 2000e. One stop clinic for assessment of risk for fetal anomalies: A report of the first year of prospective screening for chromosomal anomalies in the first trimester. Br J Obstet Gynaecol 107: 1271-1275.

Spencer K, Crossley JA, Aitken DA, Nix ABJ, Dunstan FDJ, Williams K. 2002. Temporal changes in maternal serum biochemical markers of trisomy 21 across the first and second trimester of pregnancy. Ann Clin Biochem 39:567-576.

Spencer K, Crossley JA, Aitken DA, Nix ABJ, Dunstan FDJ, Williams K. 2003a. The effect of temporal variation of biochemical markers of trisomy 21 across the first and second trimester of pregnancy on the estimation of individual patient-specific risks and detection rates for Down's syndrome. Ann Clin Biochem 40:219-231.

Spencer K, Spencer CE, Power M, Dawson C, Nicolaides KH. 2003b. Screening for chromosomal abnormalities in the first trimester using ultrasound and maternal serum biochemistry in a one stop clinic: A review of three years prospective experience. $\mathrm{Br} \mathrm{J}$ Obstet Gynaecol 110:281-286.

Spencer K, Crossley JA, Aitken DA, Nicolaides KH. 2005. Second trimester levels of pregnancy associated plasma protein-A and free beta hCG in pregnancies with trisomy 13. Prenat Diagn 25:358-361.

Stenhouse EJ, Crossley JA, Aitken DA, Brogan K, Cameron AS, Connor JM. 2004. First trimester combined ultrasound and biochemical screening for Down syndrome in routine clinical practice. Prenat Diagn 24:774-780
Sturgeon CM, Ellis AR, Al-Sadie R, Logan M, Costa M. 2006. UKNEQAS for peptide hormones and related substances. Annual Review 2005 UKNEQAS, Edinburgh, 6677

Tul N, Spencer K, Noble P, Chan C, Nicolaides K. 1999. Screening for trisomy 18 by fetal nuchal translucency, maternal serum free $\beta$-hCG and PAPP-A at 10-14 weeks of gestation. Prenat Diagn 19:1035-1042.

Van Lith JMM, Pratt JJ, Beekhuis JR, Mantingh A. 1992. Second trimester maternal serum immunoreactive inhibin as a marker for fetal Down's syndrome. Prenat Diagn 12:801806.

von Kaisenberg CS, Gasiorek-Wiens A, Bielicki M, Bahlmann F, Meyberg H, Kossakiewicz A, Pruggmayer M, Kamin G, Fritzer E, Harris C, Arnold N. 2002. German speaking Down Syndrome Screening group. Screening for trisomy 21 by maternal age, fetal nuchal translucency and maternal serum biochemistry at 11-14 weeks: A German multicentre study. J Matern Fetal Neonatal Med 12:89-94.

Wald NJ, Hackshaw AK. 1997. Combining ultrasound and biochemistry in first trimester screening for Down's Syndrome. Prenat Diagn 17:821-829.

Wald NJ, Cuckle HS, Wu T, George L. 1991. Maternal serum unconjugated estriol and human chorionic gonadotrophin levels in twin pregnancies: Implications for screening for Dow's syndrome. Br J Obstet Gynaecol 8:905-908.

Wald NJ, Kennard A, Hackshaw A, McGuire A. 1998. Antenatal screening for Down's syndrome. Health Technol Assess 2:1-112.

Wald NJ, Watt HC, Hackshaw AK. 1999 Integrated screening for Down's Syndrome based on tests performed during he first and second trimesters. N Engl J Med 341:461467.

Wald NJ, Huttly WJ, Hackshaw AK. 2003a. Antenatal screening for Down's syndrome with the quadruple test. Lancet 361:835836.

Wald NJ, Rodeck C, Hackshaw AK, Walters J, Chitty L, Mackinson AM. 2003b. First and second trimester antenatal screening for Down's syndrome: The results of the Serum, Urine and Ultrasound Screening Study (SURUSS). Health Technol Assess 7:1-88.

Wald NJ, Bestwick JP, Morris JK. 2006. Crosstrimester marker ratios in prenatal screening for Down syndrome. Prenat Diagn 26:514523.

Wallace EM, Crossley JA, Ritoe SC, Aitken DA Spencer K, Groome NP. 1998. Evolution of an inhibin-A ELISA method: Implications for Down's syndrome screening. Ann Clin Biochem 35:656-664

Wapner R, Thom E, Simpson JL, Pergament E, Silver R, Filkins K, Platt L, Mahoney M, Johnson A, Hogge WA, Wilson RD, Mohide P, Hershey D, Krantz D, Zachary J, Snijders R, Greene N, Sabbagha R, MacGregor S, Hill L, Gagnon A, Hallahan T, Jackson L. 2003. First trimester maternal serum biochemistry and fetal nuchal translucency screening (BUN) study group. N Engl J Med 349:1405-1413.

Wewer UM, Engvall E, Albrechtsen R. 2005 Adam 12; the long and the short of it. In: Hooper NM, Lendeckel U, editors. The ADAM Family of Proteases, Vol. 4. The Netherlands: Springer. p 123-146.

Wright DE, Bradbury I. 2005. Repeated measures screening for Down's Syndrome. BJOG 112:80-83.

Wright D, Bradbury I, Benn P, Cuckle H, Ritchie K. 2004. Contingent screening for Down syndrome is an efficient alternative to nondisclosure sequential screening. Prenat Diagn 24:762-766.

Wright D, Bradbury I, Cuckle H, Gardosi J, Tonks A, Standing S, Benn P. 2006a. Three stage contingent screening for Down syndrome. Prenat Diagn 26:528534.

Wright DE, Bradbury I, Benn P, Nix B, Spencer K, Cuckle H. 2006b. CT ratios: Parameter estimates are inconsistent with SURUSS publications? Prenat Diagn 26:991-992.

Wright D, Spencer K, Nix B. 2006c. First trimester repeated measures screening for Down's syndrome. Prenat Diagn 26:991992. 